Vol. 3, No. 3, July 2018, 107-112

Webpage: http://rheumres.org

Email: editor@rheumres.org

ISSN: 2476-5856

doi: $10.22631 / \mathrm{rr} .2018 .69997 .1050$

(C)2018, Iranian Rheumatology Association

\title{
IL-17A gene polymorphism at position G197A and systemic lupus erythematosus
}

\author{
Mahboobeh Sharifzade ${ }^{1}$, Sirous Naeimi ${ }^{2 *}$, Mahboobeh Nasiri ${ }^{1}$, Saiedeh Ariannia ${ }^{3}$, Reza Farrokh Seresht ${ }^{4}$ \\ ${ }^{l}$ Department of Biology, Arsanjan Branch, Islamic Azad University, Arsanjan, Iran; ${ }^{2}$ Department Of Genetics, Kazerun Branch, \\ Islamic Azad University, Kazerun, Iran; ${ }^{3}$ Department of Rheumatology, Loghman e Hakim Hospital, Shahid Beheshti University of \\ Medical Sciences, Tehran, Iran; ${ }^{4}$ Department of Internal Medicine, Faculty of Medicine, Hormozgan University of Medical Sciences, \\ Bandar Abbas, Iran
}

\begin{abstract}
Systemic lupus erythematosus (SLE) is a multi-systemic disorder with various clinical manifestations. Lupus is a multifactorial autoimmune disease resulting from complex gene-environment interactions. IL-17 is a pro-inflammatory cytokine secreted by Th-17 cells, and IL-17A and IL-17F are two predominant members of this family. The present study assessed the association of IL-17F (rs763780) gene polymorphism with SLE. A total of 102 SLE patients and 141 healthy subjects were enrolled in this case-control study. Genotyping was done using the PCR-RFLP technique. The results were analyzed using SPSS software. Results showed a borderline relationship between the heterozygote genotype (AG) and a reduced risk of SLE (OR: 0.31, 95\% CI: 0.09-1.0, $P=0.05$ ). The A allele was also shown as having a protective effect on SLE susceptibility (OR: 0.68, 95\% CI: 0.46$1.0, P=0.05$ ). No association was observed between the genotypes of the IL-17F gene polymorphism and the risk of SLE $(P>0.05)$. In conclusion, it seems that the IL-17A gene may be involved in the pathogenesis of SLE.
\end{abstract}

Keywords: genotype, polymorphism, rs2275913, rs763780, SLE.

\section{Introduction}

Systemic lupus erythematosus (SLE) is considered to be an autoimmune disease which results in extensive clinical manifestations by affecting various organs [1]. The estimated prevalence of SLE is $20-150$ per 100,000 individuals $[2,3]$, and the ratio of females to males is $9: 1$, particularly affecting women of childbearing age [4]. The etiology of SLE is not completely understood. Environmental, immunologic, hormonal, and genetic factors play a critical role in the development of SLE [5]. It is known that the activation of the immune system, such as Hyperactive B and T cells, and loss of immune tolerance lead to the spectrum of clinical manifestations of SLE [6]. Many genes are involved in the pathogenesis of SLE, including HLA-DR, IRF5, BANK1, Fc $\gamma$ RII, Tap1 and Tap2, ITGAM, PIPN22, C2, C4, and CD19 [7]. Important hallmarks of SLE are abnormal cytokine levels, particularly interleukin 6, BLys (B Lymphocyte stimulators), IL-17, IL-18, Interferons and tumor necrosis factors (TNFs) [8]. Studies show that the plasma IL-17 level has a positive correlation with the pathogenesis of SLE [9]. The IL-17 family consists of 6 members: IL-17A,
IL-17B, IL-17C, IL-17D, IL-17E, and IL-17F. From these cytokines, IL-17A and IL-17F have been studied more and have the highest degree of homology [10]. The IL-17A and $\mathrm{F}$ genes are located on chromosome $6 \mathrm{p} 12$. The binding of IL-17F and IL-17A to their receptors leads to the activation of NF-KB, MAPK, and C/EBP transcription factor pathways and, consequently, the expression of proinflammatory cytokine genes [11, 12]. Furthermore, it results in the stabilization of some chemokine mRNAs by another pathway. An imbalance in these two signaling pathways can provide autoimmune disease predisposition [13]. Previous studies have reported the importance of IL17A rs2275913 and IL17F rs763780 polymorphisms in the pathogenesis of some human diseases, such as rheumatoid arthritis, psoriasis, and gastric cancer [14-17].

The current study is the first to study the relationship of IL17A (rs2275913) and IL17F (rs763780) polymorphisms with susceptibility to SLE in patients from southern Iran.

\section{Materials and Methods Patients and Controls}

This case-control study was performed on 102 SLE-

\footnotetext{
* Corresponding Author: Sirous Naeimi, E-mail: naeimis@kau.ac.ir, Tel: +98 71 42230505-6
}

Received: 28 October 2017; Accepted: 28 February 2018 
affected patients and 141 healthy individuals. The confidence level of population enrolled in this study was predicted to be about $95 \%$ with respect to $(\alpha=5 \%)$. The patients were selected from among patients referring to the rheumatology clinic of Khatam-al-Anbia Hospital, Bandar Abbas, Iran. The disease status of patients was confirmed by a specialist according to the American College of Rheumatology (ACR) Classification Criteria [18]. Age $( \pm 5)$ and sex-matched controls were selected from the same province. Detailed descriptions of the inclusion and exclusion criteria were reported in the study by Nasiri et al. [19]. All individuals (patients and controls) signed a written informed consent form before taking part in the study. This study was approved by the local committee of the Islamic Azad University, Arsanjan Branch.

\section{DNA extraction and Genotyping}

About $5 \mathrm{ml}$ of peripheral blood was taken from each participant in a standard EDTA specimen collection vacuum tube. DNA was extracted through the salting-out method [20]. Restriction fragment length polymorphismpolymerase chain reaction (RFLP-PCR) was used to examine IL-17F (rs763780) and IL-17A (rs225913) polymorphisms. Information regarding the primer sequences, restriction enzymes, cutting sites, and digestion products is given in Table 1 [21].

Each PCR condition for rs763780 consisted of $12.5 \mu 1$ Master PCR solution (Yekta Tajhiz, Iran), $1 \mu$ l forward primer, $1 \mu 1$ reverse primer, $9.5 \mu 1$ DNase free water, and $1 \mu 1$ DNA template. Primers were annealed at $62^{\circ} \mathrm{C}$, and PCR reaction was repeated for 35 cycles. For rs2275913, the PCR reaction consisted of $12.5 \mu$ l Master PCR solution, $1 \mu \mathrm{L}$ forward primer, $1 \mu \mathrm{L}$ reverse primer, $9.5 \mu \mathrm{L}$ DNase free water, and $1 \mu \mathrm{L}$ DNA template. Primers were annealed at $62{ }^{\circ} \mathrm{C}$, and the PCR reaction was repeated for 35 cycles.

The rs763780 and rs2275913 amplicons were digested by NlaIII and XagI enzymes (Fermentas, Canada) at $37^{\circ} \mathrm{C}$ for 16 hours and then electrophoresed on 3\% agarose gel to determine each participant's genotypes (Figs. 1 and 2).

\section{Statistical analyses}

To determine whether the SNP was on the HardyWeinberg equilibrium, the observed genotype frequency distributions were compared with the expected ones using the chi-square test. T-test and $\chi^{2}$ test were used to compare the continuous and nominal variables among RPL (cases) and control women, respectively. The odds ratio (OR) and a $95 \%$ confidence interval (CI) were calculated in logistic regression analysis. A value of $P<0.05$ was considered statistically significant. All statistical analyses were performed with SPSS 16.0 software.

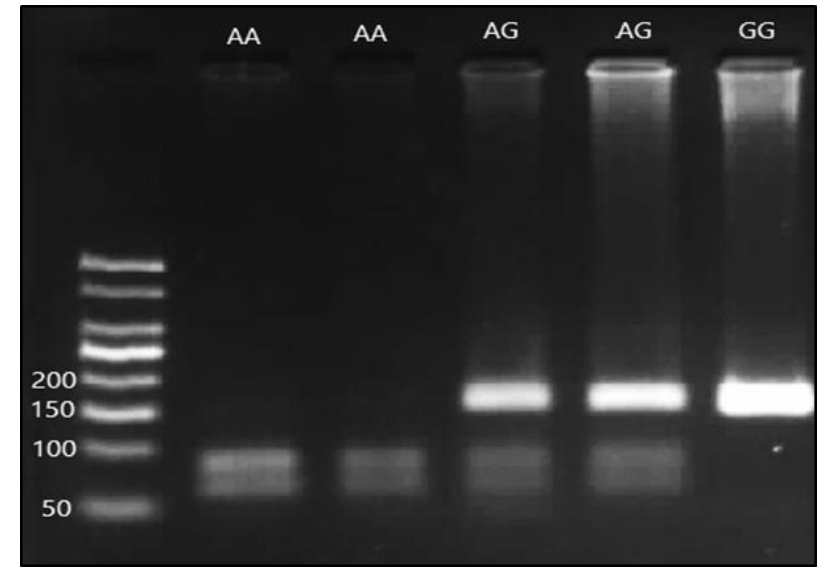

Fig. 1. rs763780 amplification digestion pattern by NlaIII Enzyme on 3\% agarose gel

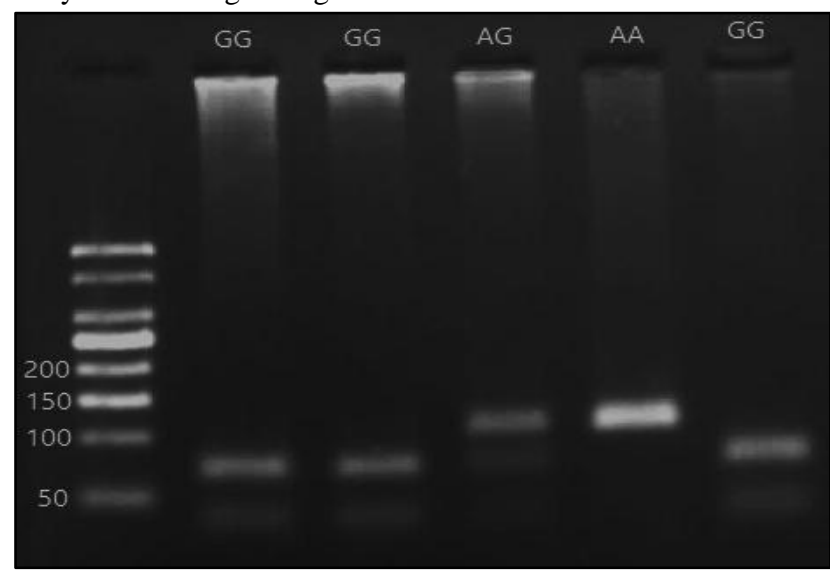

Fig. 2. rs2275913 amplification digestion pattern by XagI Enzyme on $3 \%$ agarose gel

\section{Results}

The baseline characteristics of the samples are shown in Table 2. The mean age of patients was $32.36 \pm 8.56$ years and of controls was $32.33 \pm 9.46$ years. The number of affected women was significantly higher than affected men. The observed values in the patients group regarding both rs763780 and rs225913 showed no deviation from those expected with the Hardy-Weinberg equilibrium $\left(\mathrm{X}^{2}: 3.8\right.$, df: $1, P=0.7$ and $\mathrm{X}^{2}: 2.5$, df: $1, P=0.4$, respectively).

The genotype and allele frequencies of IL-17F and IL17A gene polymorphisms in SLE patients and controls are shown in Tables 3 and 4.

Regarding the rs763780 polymorphism in IL-17F, the frequencies of the $\mathrm{AA}, \mathrm{AG}$, and $\mathrm{GG}$ genotypes among patients were $82.4 \%, 13.7 \%$, and $3.9 \%$, respectively. The comparison of these frequencies with those in the control group did not result in a statistical difference $(P>0.05)$. In the dominant model for the A allele (AA+AG vs. GG), the evaluated frequency in patients $(17.6 \%)$ compared to controls (13.5\%) was not statistically different. Neither the A nor the $\mathrm{G}$ allele were associated with SLE risk. 
Considering the effect of rs 2275913 polymorphism of IL-17A gene, the borderline effect for the AG heterozygote genotype was seen following the regression analysis (OR: $0.31,95 \%$ CI: $0.09-1.00, P=0.05)$. The frequencies of the AA genotype in controls and patients did not differ statistically. In the dominant model for the $\mathrm{A}$ allele (AA+AG vs. GG), no significant difference was seen between the case and control groups (OR: $0.64,95 \% \mathrm{CI}$ : $0.38-1.07 ; P=0.09)$. The frequency of the A allele was higher among patients compared with controls (OR: 0.68; 95\% CI: 0.46- 1.00, $P=0.05)$. On the other hand, the frequencies of haplotypes did not differ between controls and patients, either (Table 5).

Table 1. The primers, restriction enzymes and the size of RFLP products for detection of single nucleotide polymorphisms IL-17A and F

\begin{tabular}{|c|c|c|c|}
\hline $\begin{array}{l}\text { Single nucleotide } \\
\text { polymorphism }\end{array}$ & Primers & $\begin{array}{c}\text { Restriction } \\
\text { endonuclease } \\
\text { enzyme }\end{array}$ & Fragments \\
\hline $\begin{array}{l}\text { IL-17F A7488G } \\
\text { Rs763780 }\end{array}$ & $\begin{array}{l}\text { F:5'-ACCAAGGCTGCTCTGTTTCT-3' } \\
\text { R:5'- GGTAAGGAGTGGCATTTCTA-3' }\end{array}$ & NlaIII & $\begin{array}{l}\text { AA }(63 \text { and } 80 \mathrm{bp}) \\
\text { AG }(143,80 \text { and } 63 \mathrm{bp}) \\
\text { GG }(143 \mathrm{bp})\end{array}$ \\
\hline $\begin{array}{l}\text { IL-17A G197A } \\
\text { Rs2275913 }\end{array}$ & $\begin{array}{c}\mathrm{F}: 5^{\prime}-\mathrm{AACAAGTAAGAATGAAAAGAGGACATGG-3}{ }^{\prime} \\
\text { R:5'- CCCCCAATGAGGTCATAGAAGAATC-3' }\end{array}$ & XagI & $\begin{array}{l}\text { GG }(68 \text { and } 34 \mathrm{bp}) \\
\text { GA( }(102,68 \text { and } 34 \mathrm{bp}) \\
\text { AA }(102 \mathrm{bp})\end{array}$ \\
\hline
\end{tabular}

Table 2. The characteristics of the study population

\begin{tabular}{lccc}
\hline \multicolumn{1}{c}{ Characteristics } & Controls & Patients & P $^{*}$ \\
\hline Total & 141 & 102 & 0.98 \\
Mean age $(\mathrm{yr} \pm \mathrm{SD})$ & $32.33 \pm 9.46$ & $32.36 \pm 8.56$ & \\
Age range & $13-59$ & $13-59$ & \\
Sex ratio $(\mathrm{M} / \mathrm{F})$ & 5.136 & 4.98 & \\
\hline
\end{tabular}

Table 3. Association between IL-17F(rs763780) polymorphism and SLE

\begin{tabular}{cccccc}
\hline $\begin{array}{c}\text { IL-17F } \\
\text { Genotype }\end{array}$ & Control(N\%) & Patient(N\%) & $\boldsymbol{P}$ & Odd Ratio(OR) & 95CI\% \\
\hline AA & $122(86.5)$ & $84(82.4)$ & - & - & reference \\
AG & $17(12.1)$ & $14(13.7)$ & 0.64 & 0.84 & $0.39-1.78$ \\
GG & $2(1.4)$ & $4(3.9)$ & 0.22 & 0.34 & $0.06-1.92$ \\
AA+AG & $19(13.5)$ & $18(17.6)$ & 0.37 & 0.72 & $0.36-1.46$ \\
Allel & & & & - & reference \\
A & $261(93)$ & $182(89)$ & - & 0.66 & $0.36-1.25$ \\
G & $13(7)$ & $22(11)$ & 0.20 & & \\
\hline
\end{tabular}

Table 4. Association between IL-17A(rs2275913) polymorphism and SLE

\begin{tabular}{llllll}
\hline IL-17A Genotype & Control(N\%) & Patient(N\%) & $\boldsymbol{P}$ & Odd Ratio(OR) & \%95CI \\
\hline GG & $72(51.1)$ & $41(40.2)$ & - & 1 & reference \\
AG & $64(45.4)$ & $52(51)$ & 0.05 & 0.31 & $0.09-1.00$ \\
AA & $5(3.5)$ & $9(8.8)$ & 0.18 & 0.70 & $0.41-1.19$ \\
AG+AA & $60(48.9)$ & $61(59.8)$ & 0.09 & 0.64 & $0.38-1.07$ \\
Allel & & & & 1 & reference \\
G & $208(74)$ & $134(66)$ & - & 0.68 & $0.46-1.00$ \\
A & $74(26)$ & $70(34)$ & 0.05 & & \\
\hline
\end{tabular}

Table 5. The frequencies of haplotype of IL-17A (rs2275913) and IL-17F (rs763780) in patients with SLE and healthy control subjects

\begin{tabular}{ccccc}
\hline Haplotypes & \multicolumn{2}{c}{ Frequencies } & P-value \\
rs2275913 & rs763780 & $\begin{array}{c}\text { Patients } \\
\text { 2n=204 }\end{array}$ & 2n=282 & 0.52 \\
G & $\mathrm{A}$ & $171(83.4 \%)$ & $252(89.1 \%)$ & 0.078 \\
$\mathrm{~A}$ & $\mathrm{~A}$ & $15(7.4 \%)$ & $7(2.4 \%)$ & 0.33 \\
$\mathrm{G}$ & $\mathrm{G}$ & $8(3.8 \%)$ & $14(4.9 \%)$ & 0.13 \\
$\mathrm{~A}$ & $\mathrm{G}$ & $10(5 \%)$ & $9(3.6 \%)$ & \\
\hline
\end{tabular}




\section{Discussion}

Preliminary studies on Th17 cells suggested these cells had a role in inflammatory and autoimmune diseases. In recent years, studies have confirmed the magnitude of IL-17 made by different $\mathrm{T}$-cell subsets such as $\mathrm{T}$ helpers, cytotoxic $\mathrm{T}$ cells, CD3+CD4-CD8-T-cells, and $\gamma \delta$ T-cells in SLE patients [22, 23]. Moreover, Yang et al. reported a relationship between IL17-producing T-cells and clinical manifestations of SLE [24]. IL-17 and IL-23s peripheral levels are higher in SLE-affected patients [25]. The IL-17producing $\mathrm{T}$ lymphocyte is also increased in the peripheral blood of SLE patients.

In vitro studies have demonstrated that lymphocytes extracted from affected patients have higher IL-17producing capabilities than $\mathrm{T}$ lymphocytes extracted from healthy controls. On the other hand, plasma IL-17 levels have been shown to have a positive correlation with SLE pathogenesis.

Dolff et al. showed a correlation between percentages of IL-17-expressing T-cells and disease activity. Furthermore, these cells cause the high expression of costimulatory markers such as CD134 and CD80. CD134+T-cells detected in renal biopsies of SLE patients with lupus nephritis are evidence for the migration of these cells to the kidney, and it is believed that this process is involved in inflammation through IL-17 secretion [26].

Riedel et al. reported that Th17 cells have been shown to be more potent than others in the pathogenesis of autoimmune disease, which implicates the Th17 master cytokine, IL-17A, as the critical mediator. They also identified CD4+T cells and $\gamma \delta \mathrm{T}$ cells as the main cellular source of IL-17F in the inflamed kidney by using a mouse model of acute crescentic GN (nephrotoxic nephritis) [27]. In IL-17F (rs763780) gene polymorphism, singlenucleotide substitution of $\mathrm{G}$ to $\mathrm{A}$ at position 7488 in exon 3 is responsible for an amino acid change in a newlysynthesized protein. This change results in the substitution of histidine (CAT) for arginine (CGT) in protein. Since the amino acid change happens in the structural and functional part of the protein, the natural IL17F activity is altered [28].

The single nucleotide polymorphism (SNP), rs2275913 (G197A), which is located in the promoter region of the IL17 gene, can be a key regulator of gene transcription. Moreover, it has been shown that the A allele has a high affinity for nuclear factor of activated T-cells (NFAT) [29, 30]. NFAT plays a vital role in the development and function of the immune system. In a T cell, NFAT protein not only controls regulation activity, but is also involved in controlling the proliferation and self-tolerance of $\mathrm{T}$ lymphocytes and T-cell differentiation. In the present study, the relationship between IL-17 gene polymorphisms and susceptibility to SLE was considered. The association between IL-17A (rs2275913) and IL-17F (rs763780) gene polymorphisms and SLE were studied.

According to the current findings, the rs2275913 variation has a protective effect on SLE susceptibility. It was also found that those who have inherited the A allele have a significantly lower susceptibility to SLE. Shen et al. investigated IL17A polymorphisms and RA susceptibility in the Chinese population. They determined that IL17A rs4711998 A/G and IL17A rs8193037 G/A polymorphisms were not associated with RA and IL17A rs2275913 G/A and IL17A rs3819024 A/G variant alleles decreased the risk of RA, while IL17A rs3819025 G/A and IL17A rs8193036 C/T variant alleles increased the risk of RA in the Chinese population. Their findings suggest that IL17A polymorphisms may be associated with RA [31].

Hammad et al. investigated IL-17A and IL-17F gene polymorphisms as risk factors for pediatric SLE (pSLE) in a group of Egyptian children. They reported that there were no significant differences in genotype and allele frequencies between pSLE patients and healthy subjects ( $p v>0.05)$. However, they also reported that the genotype combination GGAGAA and the haplotype GGA had significant associations with pSLE ( $\mathrm{p}=0.042$ and $P<0.001$, respectively). They determined that the AA genotype of IL-17F is more frequent in female patients $(P=0.002)$, and the AA genotype of IL-17F rs2397084 is more frequently accompanied by the positivity of ds-DNA $(P=0.007)$ [32].

Bogunia-Kubik et al. investigated the relationship between IL-17A, IL-17F, and IL-23R gene polymorphisms and RA susceptibility, progression, and reaction to treatment with TNF- $\alpha$ suppressors. They discovered that female patients with the wild-type genotype of IL-17A more repeatedly were accessible with stage $4(P=0.058)$ and were considered by more active disease (the highest DAS28 score $>5.1$ ). They also reported that IL-17F gene polymorphism seemed to be associated with the disease. The presence of the IL-17F minor variant (OR 3.97; $P<0.001$ ) and its homozygosity (OR 29.62; $P<0.001$ ) were more frequent among patients than healthy subjects [33]. In this study, the rs763780 polymorphism in the IL-17F gene and SLE susceptibility in a population of southern Iran were investigated. No relationship between this variation and SLE susceptibility was found.

In summary, the current results indicate that rs2275913 of IL-17A might have a protective effect against the manifestation of SLE in an Iranian population. On the other hand, no association between IL-17F polymorphism, rs763780, and the risk of SLE was found. The small size of the sample evaluated might be the weak aspect of this research, particularly when the study samples were 
organized into indoor/outdoor or positive/negative family history groups. It is recommended that future research study the correlation in larger populations and participants from diverse geographical areas to verify these findings. Other approaches such as High Resolution Melting (HRM) may be helpful in identifying polymorphisms.

\section{Conflicts of interest}

The authors declare no conflict of interest.

\section{References}

1. Ruiz-Irastorza G, Khamashta MA, Castellino G, Hughes GR. Systemic lupus erythematosus. Lancet 2001; 357(9261): 1027-32. doi: 10.1016/ S0140-6736(00)04239-2

2. Lawrence RC, Helmick CG, Arnett FC, Deyo RA, Felson DT, Giannini $\mathrm{EH}$, et al. Estimates of the prevalence of arthritis and selected musculoskeletal disorders in the United States. Arthritis and Rheumatism 1998; 41(5): 778-99. doi: 10.1002/1529-0131(199805)41.

3. Pons-Estel GJ, Alarcon GS, Scofield L, Reinlib L, Cooper GS. Understanding the epidemiology and progression of systemic lupus erythematosus. Seminars in Arthritis and Rheumatism 2010; 39(4): 257-68. doi: 10.1016/ j.semarthrit.2008.10.007.

4. Tsao BP. The genetics of human systemic lupus erythematosus. Trends in Immunology 2003; 24(11): 595-602. doi: 10.1016/ j.it.2003.09.006

5. Maidhof W, Hilas O. Lupus: an overview of the disease and management options. P \& T: a peerreviewed. Journal for Formulary Management 2012; 37(4): 240-9.

6. Kiriakidou M, Cotton D, Taichman D, Williams S. Systemic lupus erythematosus. Ann Intern Med 2013; 159(7): Itc4-1. doi: 10.7326/ 0003-4819-159-7-20131001001004 .

7. Tahernia L, Namazi Sh, Rezaei N, Ziaee V. Cytokines in systemic lupus erythematosus: their role in pathogenesis of disease and possible therapeutic opportunities. Rheum Res 2017; 2(1): 1-9. doi: 10.22631/ rr.2017.69997.1010.

8. Connolly JJ, Hakonarson H. Role of cytokines in systemic lupus erythematosus: recent progress from GWAS and sequencing. Journal of Biomedicine \& Biotechnology 2012; 798924. doi: 10.1155/2012/798924.

9. Wong CK, Lit LC, Tam LS, Li EK, Wong PT, Lam CW. Hyperproduction of IL-23 and IL-17 in patients with systemic lupus erythematosus: implications for Th17-mediated inflammation in auto-immunity. Clinical immunology 2008; 127(3): 385-93. doi: 10.1016/j.clim.2008.01.019.

10. Moseley TA, Haudenschild DR, Rose L, Reddi AH. Interleukin-17 family and IL-17 receptors. Cytokine \& Growth Factor Reviews 2003; 14(2): 155-74. doi: 10.1016/s13596101(03)00002-9.

11. Bulek K, Liu C, Swaidani S, Wang L, Page RC, Gulen MF, et al. The inducible kinase IKKi is required for IL-17-dependent signaling associated with neutrophilia and pulmonary inflammation. Nature Immunology 2011; 12(9): 844-52. doi: 10.1038/ni.2080.

12. Sun D, Novotny M, Bulek K, Liu C, Li X, Hamilton T. Treatment with IL17 prolongs the half-life of chemokine CXCL1 mRNA via the adaptor TRAF5 and the splicingregulatory factor SF2 (ASF). Nature Immunology 2011; 12(9): 853-60. doi: 10.1038/ni.2081.

13. Doyle MS, Collins ES, FitzGerald OM, Pennington SR. New insight into the functions of the interleukin17 receptor adaptor protein Act1 in psoriatic arthritis. Arthritis Research \& Therapy 2012; 14(5): 226. doi: 10.1186/ar4071.

14. Louahchi S, Allam I, Berkani L, Boucharef A, Abdesemed A, Khaldoun N, et al. Association study of single nucleotide polymorphisms of IL23R and IL17 in rheumatoid arthritis in the Algerian population. Acta Reumatologica Portuguesa 2016; 41(2): 151-7.

15. Bialecka M, Ostasz R, Kurzawski M, Klimowicz A, Fabianczyk H, Bojko $\mathrm{P}$, et al. IL17A and IL17F gene polymorphism association with psoriasis risk and response to treatment in a polish population. dermatology (Basel, Switzerland). 2016. doi: 10.1159/000448090.

16. Liu J, Xu Q, Yuan Q, Wang Z, Xing C, Yuan Y. Association of IL-17A and IL-17F polymorphisms with gastric cancer risk in Asians: a meta- analysis. Human Immunology 2015; 76(1): 6-12. doi: 10.1016/j.humimm. 2014.12.011.

17. Liu J, Xu Q, Yuan Q, Wang Z, Xing C, Yuan Y. Association of IL-17A and IL-17F polymorphisms with gastric cancer risk in Asians: a metaanalysis. Human Immunology 2015; 76(1): 6-12. doi:10.1016/j.humimm. 2014.12.011.

18. Smith EL, Shmerling RH. The American College of Rheumatology criteria for the classification of systemic lupus erythematosus: strengths, weaknesses, and opportunities for improvement. Lupus 1999; 8(8): 586-95. doi: 10.1191/096120399680411317.

19. Ghalamkari S, Nasiri M, Ariannia S, Farrokhseresht R. G-protein coupled-receptor 65 5'UTR gene polymorphism in the pathogenesis of systemic lupus erythematosus. Rheum Res 2017: 2(4): 139-143. doi: 10.22631/rr.2017.69997.1033.

20. Ghatak S, Bose Muthukumaran R, Kumar Nachimuthu S. A simple method of genomic DNA extraction from human samples for PCR-RFLP analysis. J Biomol Tech 2013; 24(4): 224-231. doi: 10.7171/jbt.13-2404001.

21. Wu X, Zeng Z, Chen B, Yu J, Xue L, Hao Y, et al. Association between polymorphisms in interleukin-17A and interleukin-17F genes and risks of gastric cancer. International Journal of Cancer 2010; 127(1): 8692. doi: 10.1002/ijc. 25027 .

22. Crispin JC, Oukka M, Bayliss G, Cohen RA, Van Beek CA, Stillman IE, et al. Expanded double negative T cells in patients with systemic lupus erythematosus produce IL-17 and infiltrate the kidneys. Journal of Immunology 2008; 181(12): 8761-6. doi: 10.4049/jimmunol.181.12.8761.

23. Crispin JC, Tsokos GC. Human TCR-alpha beta+ CD4- CD8- T cells can derive from $\mathrm{CD} 8+\mathrm{T}$ cells and display an inflammatory effector phenotype. Journal of Immunology 2009; 183(7): 4675-81. doi: 10.4049/jimmunol.0901533. 
24. Yang J, Chu Y, Yang X, Gao D, Zhu $\mathrm{L}$, Yang $\mathrm{X}$, et al. Th17 and natural Treg cell population dynamics in systemic lupus erythematosus. Arthritis and Rheumatism 2009; 60(5): 1472-83. doi: 10.1002/art. 24499.

25. Wong CK, Ho CY, Li EK, Lam CW. Elevation of proinflammatory cytokine (IL-18, IL-17, IL-12) and Th2 cytokine (IL-4) concentrations in patients with systemic lupus erythematosus. Lupus 2000; 9(8): 589-93. doi: 10.1191/ 096120300678828703.

26. Dolff S, Quandt D, Wilde B, Feldkamp T, Hua F, Cai X, et al. Increased expression of costimulatory markers CD134 and CD80 on interleukin-17 producing $\mathrm{T}$ cells in patients with systemic lupus erythematosus. Arthritis Research \& Therapy 2010; 12(4): R150. doi: 10.1186/ar3100.

27. Riedel JH, Paust HJ, Krohn S, Turner JE, Kluger MA, Steinmetz OM, et al. IL-17F Promotes Tissue Injury in Autoimmune Kidney Diseases.
Journal of the American Society of Nephrology 2016. doi: 10.1681/ ASN.2015101077.

28. Kawaguchi M, Takahashi D, Hizawa N, Suzuki S, Matsukura S, Kokubu F, et al. IL-17F sequence variant (His161Arg) is associated with protection against asthma and antagonizes wild-type IL-17F activity. The Journal of Allergy and Clinical Immunology 2006; 117(4): 795-801. doi: 10.1016/j.jaci.2005.12. 1346.

29. Arisawa $T$, Tahara $T$, Shibata $T$, Nagasaka M, Nakamura M, Kamiya $\mathrm{Y}$, et al. The influence of polymorphisms of interleukin-17A and interleukin-17F genes on the susceptibility to ulcerative colitis. $\boldsymbol{J}$ Clin Immunol 2008; 28(1): 44-9. doi: 10.1007/s10875-007-9125-8.

30. Espinoza JL, Takami A, Nakata K, Onizuka M, Kawase T, Akiyama $\mathrm{H}$, et al. A genetic variant in the IL-17 promoter is functionally associated with acute graft-versus-host disease after unrelated bone marrow transplantation. PLoS One 2011;
6(10): e26229. doi: 10.1371/journal. pone. 0026229 .

31. Shen L, Zhang H, Yan T, Zhou G, Liu R. Association between interleukin 17A polymorphisms and susceptibility to rheumatoid arthritis in a Chinese population. Gene 2015; 566(1): 18-22. doi: 10.1016/j.gene. 2015.04.028

32. Hammad A, Mosaad YM, Hammad EM, Elhanbly S, El-Bassiony SR, Al-Harrass MF, et al. Interleukin17A rs2275913, Interleukin-17F rs763780 and rs2397084 gene polymorphisms as possible risk factors in Juvenile lupus and lupus related nephritis. Autoimmunity 2016; 49(1): 31-40. doi: 10.3109/ 08916934.2015.1101071.

33. Bogunia-Kubik K, Swierkot J, Malak A, Wysoczanska B, Nowak B, Bialowas K, et al. IL-17A, IL-17F and IL-23R Gene Polymorphisms in Polish Patients with Rheumatoid Arthritis. Archivum Immunologiae et Therapiae Experimentalis 2015; 63(3): 215-21. doi: 10.1007/s00005$014-0319-5$. 